\title{
12 Years Of Action Learning At EM Normandie: Monitored Field Projects As Regular Pedagogical Activities
}

Sophie Gay Anger, EM Normandie and NIMEC, IAE Caen, France

Virginie Hachard, EM Normandie and NIMEC, IAE Caen, France

\begin{abstract}
The Master Grande Ecole curriculum at EM Normandie School is organized around junior consulting projects and real problem solving activities aiming at bridging the gap between classroom knowledge and professional competencies. Since the 90's, students are involved in regular consulting activities for local and national companies following the 'HEC entrepreneur' pedagogy adapted guidelines. The purpose of this paper is to characterize the EM Normandie junior consulting projects learning activities within the more general theoretical framework of Action Learning. We underline the elements that make action leaning at EM Normandie singular, but also its limits and potential for improvement.
\end{abstract}

Keywords: Action Learning; Management Education; Field Projects

\section{INTRODUCTION}

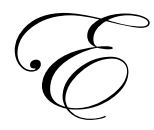

M Normandie has developed since the 90's its own pedagogical framework based on Action Learning (AL) principles. AL activities are recurrent in the curriculum of the students, present in each year of the Master's program and representing significant part of their performance evaluation.

The aim this paper is to present the specifics of AL at EM Normandie, in particular its theoretical background and practical choices in order to shed a new light on how to use AL as a recurring learning activity in an educational context. Although AL is acknowledged as a meaningful way to promote managerial learning, its pedagogic use in a higher education context has gathered limited attention in the literature (Gabrielsson et al., 2010).

After a presentation of AL and its different schools of thought, we will specify the theoretical framework of $\mathrm{AL}$ at EM Normandie and provide a detailed presentation of the junior consulting project activity. Finally, we will discuss the limits of the EM Normandie model and propose different ways of improvement.

\section{ACTION LEARNING IN BUSINESS SCHOOLS}

Reg Revans is unanimously acknowledged as the father of «Action Learning » in the literature, yet this consensus does not extend to the definition of AL itself due to a choice of different theoretical backgrounds from authors in the field (Nufrio and Tietje, 2004) but also to opposing views about the necessity to define AL (Simpson and Bourner, 2007).

What is AL? It is a form of learning based on experience - learning not only by doing but by "doing different" (Simpson and Bourner, 2007)- where learners work in small groups to solve a specific and complex problem by building on what is rather than on what should be (York et al., 1999). Action Learning is different from Active Learning, which in a broader sense refers to any activity requiring the active involvement of the student (Prince, 2004). Active learning focuses on discussion and reaction, not to real situations but to simulations or reenactment of them. Its objective is to complement the formal knowledge transfer by establishing links between 
concepts and action, but a simulated and out of context kind of action. The much debated Case Study constitutes the emblematic example of active learning.

According to Raelin (2009), active learning activities were developed after sustained critic from the professional world against young MBA's being too analytical, short term oriented, narrow minded and showing little interest for longer term learning and self development ${ }^{1}$. But, as Raelin demonstrates, active learning, because it remains out of context, does not allow for a holistic form of learning.

AL promoters consider in fact that management learning consists in learning how to act in a real work situation (Revans, 1998). This goes beyond a conceptual analysis of a problematic situation and implies direct contact and discussion with other managers and workers. AL as a consequence necessarily results in personal development but also in an "organizational" development of participants.

Although various forms of AL exist, all share two essential characteristics (Marsick, 1999): action in a real context and learning by shared experience. Learners are faced with a complex and real management problem by teams of 4 to 6 individuals. A manager, or corporate supervisor, answers the learners' questions; is closely involved in the problematic and is a decision maker in the company. An independent coach, not a technical expert, supports the group in the questioning process.

In practice, 4 different schools of AL implementation exist: the tacit school, the scientific school, the experiential school and the critical reflection school (O’Neil (quoted by Yorks et al. (1999); O'Neil and Marsick, 2007).

The scientific school is closely linked to the work of Reg Revans and consequently gives special importance to critical questioning as shown by the equation:

Learning $(\mathrm{L})=$ Programmed instruction $(\mathrm{P})+$ Questioning insight $(\mathrm{Q})$

P refers to book or class consensus knowledge: theories, techniques and approaches that have demonstrated their efficiency in the past (Yorks et al., 1999). Q in contrast, refers to a questioning capacity that enables the manager to interpret experience in a new way. Q, a questioning insight is "intuition, things crossing the mind, insight" (Revans, 1989).

The tacit or incidental school supposes that learning occurs in a non planned way, as learners gather and work on a specific management problem. It is the only approach not involving a coach as it believes that learning cannot be planned, it just "happens".

Kolb's work (1984) and the experiential learning cycle are the sources of the experiential school. The focus is on intentional reflection supported by a learning coach. Learners reflect on their experience and are able to develop new forms of action.

The critical reflection school goes deeper in the examination of beliefs and perceptions that influence the reflection process of the learners. This is done in order to question given-for-granted solutions, organizational norms and perceptions (Yorks et al., 1999).

EM Normandie pedagogical framework, as far as AL is concerned, is linked to the scientific school, and in particular to the practical model developed by Marquardt (2004). This model is specifically suited to an academic context as will be demonstrated in the next section.

\footnotetext{
${ }^{1}$ During the last decade, management education and Business schools have been heavily criticized for the focus on scientific rigor and abstract thinking (Chia and Holt, 2008). In the words of Gabrielsson et al. (2010):" ... aspiring managers learn about the practice of management instead of developing their skills to practice it."
} 


\title{
THE MARQUARDT FRAMEWORK AND THE EM NORMANDIE EARLY MODEL
}

\author{
M.J. Marquardt's AL (2004) model is characterized by six basic components:
}

A problem or challenge which is "of high importance to an individual, team, and/or organization". The problem should also be urgent and it should not have an easily identifiable solution. Learners are responsible for finding such a solution.

(ii) An AL group or team composed of four to eight individuals. The group should have "diversity of background and experience" to acquire various perspectives and to encourage fresh viewpoints.

(iii) A process of insightful questioning and reflective listening. The focus is mainly on questions which enable to identify possible solutions before taking action. It also contributes to group dialogue and cohesiveness.

(iv) An action taken by the group itself or at least the assurance the group's recommendations will be implemented. It is a mandatory basis for the critical dimension of reflection.

(v) A commitment to learning. AL places the same emphasis on the learning and development of individuals and the team as it does on the solving of problems.

(vi) An AL coach who helps the group focus on the important aspect of the problem as well as on the urgency to find a solution; he/she also helps team members reflect on what they are learning and on how they are solving problems. The coach is either a member of the group or not.

$\mathrm{AL}$ is further empowered when the two following rules are respected:

- Recommendations should only be made in response to questions; people should think "questions first" which enhances listening and reflecting. In AL, Marquardt sustains that there is a direct relation between the number and quality of questions and the eventual final quality of the actions and learnings.

- $\quad$ The AL coach has the power to intervene; his/her essential role is to help the group learn; he is not involved in the resolution of the problem.

The AL model developed by Marquardt is based on a vast experience on short term actions in a professional context: companies, public institutions, small and medium -sized firms all over the world.

The EM Normandie current model is closely related to the Marquardt model applied to an educational context. It was initially adapted from the concept developed by Robert Papin for the most famous French business school: HEC Paris; and was implemented first in the Entrepreneurship Major of the Master's program.

EM Normandie (at that time ESC Le Havre) took the strategic decision in 1998 to implement the "pédagogie HEC ${ }^{2}$ Entrepreneurs" model in the three year Grande Ecole Master's program, in partnership with HEC and Mr Papin. After 12 years, although the model is still in place, it has continuously evolved in association with the development of the School (number of students multiplied by 4) and the increasing importance given to AL in the learning process. Let's now present in more details our model.

\section{THE SPECIFICS OF THE EM NORMANDIE MODEL}

AL is embodied by monitored field projects (MFP) supervised by the academic coordinator for each year of the Master's program. Each MFP is designed to achieve 5 main learning objectives: to develop (i) professional adaption; (ii) team work and leadership abilities; (iii) critical thinking and hindsight; (iv) the capacity to formulate recommendations and support them with valid and convincing arguments; (v) the ability to present in a professional and convincing way the result of their work.

In practice, three to four students work during five weeks on a real problem submitted by the manager of the company they must report to. The final objective for the group is to make clear recommendations to the manager as how to solve the problem. The project ends with an oral presentation in front a professional jury and the submission of a final report.

\footnotetext{
${ }^{2}$ HEC Paris is French leading management school that created a form of AL activity more than 30 years ago specifically for students specializing in entrepreneurship.
} 
Each MFP is related to a specific field of management sciences: Marketing, Finance, Organization, Entrepreneurship, HR management, Logistics ... As students evolve in the program they will face work-related problems increasing in complexity and specialization: the first MFP deals with information management and business competition watch whereas final year MFPs deal with complex problems linked to each Major. For instance, students specialized in Finance must find solutions related to the implementation of a cost accounting system or improve the financial data analysis process in a corporation ${ }^{3}$.

Student performance is evaluated in three different ways: first the supervisor in the company evaluates the individual implication of each member of a group; then for each group the quality of the oral presentation of recommendations is assessed; finally a report summarizing the approach, analysis and recommendations of each team is marked by a professor of EM Normandie. Three performance evaluations are consequently collected, one individual and two for the group.

In order to obtain an EM Normandie Master's degree each student must achieve at least three MFPs which makes AL a recurring activity during the whole curriculum. This allows to progressively develop the students' capacity to face real problems for which no preformatted solution exist as well as to set increasingly demanding learning objectives. For example, the first mission focuses on team work and discussion on a clearly delimited subject (strategic information watch) ${ }^{4}$, whereas the last field project in the curriculum is much more challenging in terms of problem solving, time management and strategic recommendations. What differentiates the EM Normandie model from other AL experiments is the fact that MFPs run throughout the program and are structured as a whole.

As described in the Marquardt model, each MFP includes the following 6 basic components:

THE PROBLEM - Projects are selected by the pedagogical team in order to fit the requirements of the 1rst component: a problem of high importance for the organization, having no preformatted solution and submitted by managers with decision making power. Corporate management expects the students to provide a new perspective on the problem. Academic requirements impose the submission of a final report.

THE TEAM - Students work in groups of 3 to 4 members. Students' teams are chosen by the head of the program in order to associate learners with different profiles and backgrounds.

THE QUESTIONING PROCESS - Although a formal questioning process is not put forward, students enter into a dialogue with the manager of the company in order to reformulate the problem they have to solve. This team reformulation exercise is mandatory during the first 2 to 3 days of the project and is supported by a coach.

IMPLEMENTATION - Considering the educational context in which the project takes place, recommendations may not always be implemented. Students have to convince the manager of the pertinence of their recommendations and have him/her implement them.

COMMITMENT TO LEARNING - EM Normandie widely communicates and promotes its specific pedagogical model which implies that students deliberately choose this model before integrating the school for a two to five years period. Furthermore, MFPs account for a significant number of ECTS credits which enhances the importance given to that pedagogical experience. Thanks to these two factors, the system in place ensures the commitment of the students to acting and learning, although their degree of self motivation may vary.

COACHING - Students meet their coach twice over the 5 weeks period. The first meeting occurs within the first week of the project in order to ensure that the students have appropriately identified the problematic and method. The coach may also indirectly impact the contents of the project by helping the students consider the problem with hindsight. The second meeting is centered on the quality of recommendations and takes place approximately a week before the final jury. As students work on MFPs each year, the content of the coaching sessions is adapted to the

\footnotetext{
${ }^{3}$ As indicated previously, the HEC Entrepreneur initial concept was extended by EM Normandie with the help of Robert Papin to a much wider range of topics than Entrepreneurship.

${ }^{4}$ For more details on the initial MFP at EM Normandie, see Llosa et al. (2009).
} 
maturity, knowledge and autonomy of the students. Contrary to the prescription of the Marquardt model, coaches are selected for their expertise in the specific business field of the project as well as their pedagogic ability to transfer information.

According to Marquardt (2004) two additional rules guarantee the empowerment of AL: a "question first" approach and the remoteness of the coach from the problem. These two rules have been adapted in consideration of the academic context and the two specific constraints it generates: limited time available (only 5 weeks for each MFP) to understand the problem and an ongoing knowledge acquisition from the learners. Both constraints lead first to focus on results (or action) rather than on the questioning process. Second, the role of the coach was reconsidered in order to include technical expertise. Coaches do not give indications about a solution to the problem; they only correct technical mistakes and still support above all the capacity of the group to ask the right questions.

Besides the differences mentioned above, the long term experience gained through MFPs lead us to identify the limits of the EM Normandie model and allows us to bring forward recommendations for improving the learning process as conceived by AL.

\section{PRACTICAL LIMITS OF THE MODEL AND POTENTIAL FOR IMPROVEMENT}

As said before EM Normandie organizes MFPs on a large scale: more than 600 MJCPs are carried out each year, involving all Master's students of the institution. This generates 3 main types of operational difficulties:

(i) Impossibility for the academic supervisor to closely monitor each team and for coaches to adequately support the questioning process;

(ii) Within each MFP topic, all projects cannot possess the same level of complexity and consequently do not offer the same level of challenge to the student. This implies that in some cases students deal with puzzles rather than problems as underlined by Revans (1983);

(iii) The necessity to assess the performance generates distortions. Assessment is done by individuals independent from the company and consequently not always able to assess the quality of the questioning process. Moreover, MFPs are team work, consequently most of the assessment deals with the group and not with the individual.

(iv) In terms of external recognition, it is also difficult to express the value adding dimension of AL activities in an academic context where only individual assessment is effectively taken into consideration and internships are the only business world recognized experience. That is why it requires a strong strategic intent and a deep conviction from the top management of the institution in order to maintain such a costly activity in terms of internal human resources.

As indicated above, the formal importance of the questioning process and the evaluation of its quality may be one of the main limits of the EM Normandie AL model implementation. That is why we think that the model could be improved by implementing a final MFP where the role of the coach would be limited to supporting the questioning process and evaluating its quality for each learner.

\section{CONCLUSION}

Business Schools have a mission to educate future managers and develop their ability to face efficiently real life managerial situation. In order to reach this objective, EM Normandie has chosen to implement an AL centered approach. The model is unique in so far as it has institutionalized AL activities and structured them throughout the EM Normandie Master's program in order to bridge the gap between classroom knowledge and professional competencies. After 12 years of experience, EM Normandie has designed MFPs such as to build a consistent professional profile for its graduate students: capable of critical questioning, adaptable, result-oriented and open-minded. The model can still be improved, in particular as far as coaching, pertinent questioning and assessment of individual learning are concerned. 


\section{AUTHOR INFORMATION}

Sophie Anger, Ph.D, CFA, Joined EM Normandie in 2008 as a professor of Finance and researcher, she is the academic coordinator for the Master 1 year in International Management. She earned her Ph.D. from Laval University, Canada then worked as lecturer in Switzerland and the UK. She also worked in the banking industry, first as an analyst then as a risk manager. Her areas of research cover risk management, women entrepreneurship and finance education. E-mail: s.anger@normandie.fr

Dr Virginie Hachard, Joined EM Normandie in 1996 as a researcher and professor of accounting and finance after a carreer in audit. She is the academic coordinator of the Master2 major in Audit and Finance. She earned her doctorate from the University of Caen Basse-Normandie in the specific field of entrepreneurship. Her areas of research cover effectuation theory, entrepreneurship and micro-entreprises and finance education. E-mail: v.hachard@ normandie.fr

\section{REFERENCES}

1. Chia, R. and R. Holt, 2008. The nature of knowledge in business schools. Academy of Management Learning and Education, 7 (4), pp.471-486.

2. Dilworth, R., 1998. Action learning in a nutshell. Performance Improvement Quarterly, 11 (1), pp.28-43.

3. Gabrielsson, J., Tell, J. and D. Politis, 2010. Business Simulation exercises in small business management education: using principles and ideas from action learning. Action Learning: Research and Practice, 7 (1), pp.3-16.

4. $\quad$ Kolb, D., 1984. Experiential learning. Prentice-Hall Englewood Cliffs, New Jersey.

5. Marquardt M.J, 2004. Optimizing the power of Action Learning, Davies-Black Publishing, Palo Alto, California.

6. Marquardt, M. and D. Waddill, 2004. The Power of Learning in action learning: a conceptual analysis of how the five schools of adult learning theories are incorporated within the practice of action learning. Action Learning: Research and Practice, 1 (2), pp. 185-202.

7. Llosa, M., Guédon, J. and L. Bégin, 2009. Maîtriser l'information, une compétence mise à l'honneur à l'EM Normandie. EM Normandie \& Métis working paper, $n^{\circ} 62,25 \mathrm{p}$.

8. Marsick, V. and O'Neil, J., 1999. The many faces of action learning. Management Learning, 30 (2), pp.159-176.

9. Nufrio, P., Tietje, L., 2008. The theory and practice of action learning in the program at metropolitan college of New York. Public Administration Quarterly, 32, pp.214-242.

10. O'Neil, J. and V. Marsick, 2007. Understanding action learning. AMA innovation in adult education, New York.

11. Pedler, M., Burgoyne, J. and Brook, C., 2005. What has action learning learned to become? Action Learning: Research and Practice vol.2 (1), pp.49-68.

12. Prince, M., 2004. Does active learning work? A review of the research. Journal of Engineering Education, 93, July, pp.223-232.

13. Raelin, J., 2009. The practice turn-away: 40 years of spoon-feeding in management education. Management Learning, 40 (4), pp.401-410.

14. Revans, R., 1983. Action learning: its origins and nature. In: M.Peddler ed. 1991. Action learning in practice. Gower Publishing, $2^{\text {nd }}$ edition.

15. Revans, R., 1998. Sketches in action learning. Performance Improvement Quarterly, 11 (1), pp.23-27.

16. Simpson, P. and Bourner, T., 2007. What action learning is not in the 21st century. Action Learning: Research and Practice, 4 (2), pp.173-187.

17. Yorks, L., O'Neil, J., Marsick, V., 1999, Action learning theoretical bases and varieties of practices. Advances in Developing Human Resources, vol. 1 (2), pp.1-18. 